\title{
On the Component of Design Beauty in the Design Aesthetics Principles
}

\author{
Fei Guo \\ School of Art and Design \\ Guilin University of Electronic Technology \\ Guilin, Guangxi, China 541004
}

\begin{abstract}
As a branch of aesthetics, design aesthetics is related to the relationship between man and reality, which belongs to the opened field of academic researches. Principles of design aesthetics, the phenomenon of design art, the aesthetic creation and acceptance of the design art, the aesthetic temperament, psychology, experience, etc., are all the main objects or contents of the subject's research. Moreover, design beauty is one of the core components of the study of principles of design aesthetics. In this paper, three issues"design aesthetics and design beauty", "the internal structure in design beauty", and "emotional expression which reflects emotional beauty" are briefly discussed.
\end{abstract}

Keywords-design aesthetics; design beauty; form and formal beauty; emotional beauty and emotional expression

\section{Design AESTHETICS AND DESIGN BEAUTY}

Beauty is the embodiment of spiritual strength in human wants and also a kind of psychological effect produced by special relation between images. It can cause the aesthetic pleasure of aesthetic subject. In some sense, beauty is the high unification of form and content. And this unification is just the basis for of perceptual existence of beauty. The reason why beauty can be measured by people's heart is that the essence of beauty is the objectification and perceptual appearance of people's essential power. On the other hand, the pursuit of beauty is one of the social natures of people. Besides, this kind of pursuit is everlasting, boundless and indispensable in the whole survival process of human beings. Beauty is ubiquitous. It exists in our material and spiritual life. Especially in the aspect of living quality of modern people, no matter the material or perceptual level of beauty, or the spiritual or rational level of beauty; no matter natural beauty or artistic beauty, the core this is always beauty.

Aesthetics is also called artistic view or aesthetic standard. It is the philosophical interdisciplinary subject closely related to philosophy, psychology, theory of literature and art and even natural science, focuses on researching the problem of relationship between art and reality, also called the aesthetic relationship between human and reality. Design aesthetics is a branch of aesthetics, an emerging category of applied aesthetics, and humanities with the cross and integration of many components such as design science, sociology, culturology and aesthetics. Design aesthetics is a unique academic world related to the aesthetic relationship between human and reality and also an open and historical academic field. Here, it mainly researches the aesthetic contents and factors of all design activities including principles of design aesthetics, phenomenon of design art, the aesthetic creation and acceptance of design art, the aesthetic temperament, aesthetic experience, and aesthetic psychology of design. The nature of design art and aesthetic rule of design are the primary research objects of design aesthetics. It naturally involves the relationships between human and thing, function and form, as well as subjective creation and objective limitation. Besides, there are three methods to research design aesthetics, including linking theory with practice, history and logical analysis and philosophical analysis. To sum up, the establishment of design aesthetics discipline has important theoretical and practical significance. On one hand, design aesthetics can reach the objective of popularizing aesthetic education through summarizing phenomenon and problems of design art that the general publics have been accustomed to and researching on relevant aesthetic theory; on the other hand, the close integration of theory and practice of design aesthetics lay foundation for promoting the further development of aesthetic theory and new aesthetic creation.

- Design aesthetics is the way of manifestation of truth revealed by artistic works of design, the inevitable product of practical activity of artistic creation of design, but it still has the property of ideological form although it needs to be embodied through physical forms. The particularity of design aesthetics lies in:

- The complexity of requirements of aesthetic subject and richness and diversity of aesthetic objects determine that design aesthetics has he characteristics of "reality existence of multiple beauties" integrated from a variety of aesthetic forms such as artistic beauty, natural beauty, beauty of science and technology and social beauty;

- The property of cultural creation in practical activities of design art determines that as the public product of the masses, design aesthetics becomes the cultural and social embodiment that contains rich results of spiritual creation and accumulates profound social historical and cultural information; 
- The original objective and essence of design art and the rational beauty of design aesthetics determine that the utilitarianism contained by design aesthetics is far beyond the utilitarianism of other arts;

- The creative process of design art makes aesthetic idea closely connect with specific utility function, and then makes the modeling activity namely the design art have multiple viewpoints that are different from ordinary painting;

- As a kind of design art with obvious material action of utilitarianism, it can rise to specific aesthetic realm only by surpassing its utilitarianism, and then make the realm have dynamic, open, harmonious, humanized and individualized characteristics with rich meanings;

- From the viewpoint of composition and manifestation of design aesthetics, it has many aesthetic properties such as simple natural beauty, straightforward beauty of strength, exaggerated beauty of momentum, exquisite feminine beauty and metaphorical beauty of connotation.

\section{INTERNAL STRUCTURAL LEVELS IN DESIGN BEAUTY}

Since design aesthetics is one of the categories of applied aesthetics, it means as a design art of applied art, design aesthetics also has aesthetic characteristics and requirements of general arts. All artistic works of human have aesthetic nature, or we can say all excellent artistic works should be beautiful. The reason why excellent artistic works of design have attractive artistic charm is that all of them have strong aesthetic powers, which are enough to make people get enlightenment and enjoyment and arouse people's pursuit for beauty and consider the essential power of human themselves. In the process of designing environment, space and object, the creation subjects of design art not only create various forms, but also infuse their inner passions. They endow the works with specific appearance characteristics and power of appearance. On one hand, it makes the essence of beauty become more vivid and stronger; one the other hand, it highlights the information contained by these design forms and the function of conveying of emotion. This shows that beautiful and attractive form, elegant and strong emotion and scientific and reasonable function are always the aesthetic objectives pursued by design art. And the corresponding formal beauty, emotional beauty and functional beauty form the three internal structural levels of design aesthetics in artistic works of design.

Mr. Fang Siwen gives a brief discussion on the internal relations of the above three different levels in his book of Introduction to Art and Design that "Among three of them, the functional beauty is the basis. If there isn't functional beauty, it is impossible to discuss formal beauty and emotional beauty; formal beauty is the further deepening of functional beauty and it is also an important starting point of emotional beauty, which is the highest state in design. Functional beauty and formal beauty have lay foundation for it." Then the author analyzes characteristics of the three levels and thinks that the functional beauty and formal beauty can be materialized and expressed through various visual forms (such as space, size, form, color and light, etc.). The function of emotional beauty with extra implication and emotions lies in that it can realize the aesthetic purpose of using the limited to express the infinite.

However, in order to further deepen the description for the internal structural level of design beauty, we think it is necessary to properly supplement the form and formal beauty in design art, because as the most important element in all modeling activities, formal beauty occupies an extremely important position in the whole aesthetic field. It is well-known that forms are externalization of specific concepts. Art is the creation of symbolic form of human emotions. The purpose of any formative art is to depict visual forms. Although the aesthetic forms of art differ in thousands of ways, the essence of their beauty is the same. All forms of design art with the property of "expression" show people's physical and mental beauty of sentiment and pleasant beauty. While as a specific symbol, design art has the basic function of formalizing people's internal experience, or we can say it endows specific forms for the expression of human emotions and experience or various characteristics of their inner life. In addition, design art "is also a form that has logical similarity and consistency with the inner emotions of human beings and a special logical form. Although it is static, its connotation is dynamic. It uses static forms to show and reemerge with the ever-changing, subtle and unpredictable dynamic forms of human emotions. Artistic form is the correspondence of static form and dynamic form. Meanwhile, artistic form has the same structure with the forms of human emotion logically. Therefore, as a special logical form, art is the unification of the abstract and concrete as well as the unification of the static and dynamic." [1] Moreover, the artistic form of design has specific movement and change of inner rhythm logically. The above analysis shows that form occupies an important position in the field of design art and makes the aesthetic functions of design aesthetics in the level of formal beauty become more obvious and more important than the levels of functional beauty and emotional beauty in some sense.

The formal beauty of artistic works of design reflected by artistic form is a kind of visual sense of joy and an inner psychological reaction of people for external objective things. It derives from the regular reasonable integration of form factors in nature and life, and specific feelings of people acquired from the existential practice (life and work) of themselves and the imitation of natural phenomenon. From the "simple beauty" closely related to survival in the early stage of human civilization to "nature beauty" after experiencing periodic cyclic changes, in this duration, one of the important reasons why artistic form continuously renovates is that the appearance of any new formal beauty is the new adaptation and pursuit for social and mental development and change. Nevertheless, the fundamental rule followed by formal beauty never changes. It is the dynamic "harmonious" principle full of sense of order and embodies internal and external relations between objects and 
emphasizes the pleasant and ecological characteristics. This rule is often reflected by means such as diversification and unification, harmony and contrast, balance and symmetry and ratio scale.

Finally, the basic connotation of formal beauty in design art is the implication and emotion of representation. When grasping through intuitive manners, people will feel a kind of vitality from it. This is the rhythmic and dynamic form of artistic life in artistic works of design. This kind of formal beauty not only has its unique performance object, but also has special representation. It shows the unification of the static and dynamic as well as the unification of the abstract and concrete.

\section{EMOTIONAL EXPRESSION WHICH REFLECTS EMOTIONAL BEAUTY}

Just as discussed above, in design aesthetics, with extra implication and emotions, the emotional beauty that serves as the main means to realize the aesthetic purpose of using the limited to express the infinite is the highest state of design art, and also an invisible temperament after sublimation. As an internal structural level in design beauty, emotional beauty is embodied by aesthetic emotion penetrated by aesthetic subject in works. It can be proved from the following two aspects.

On one hand, from the perspective of principle of design aesthetics, we can say that the so-called aesthetic activity is the creation and appreciation of people for design art. Aesthetic activities closely connect with affective activities all the time. In aesthetic activities of design art, once the specific and vivid artistic images of aesthetic object (aesthetic subject) act on aesthetic subject, it will cause some kind of subjective feeling and emotional response. It is the central meaning of the word "aesthetic feeling" mentioned in aesthetics. The "art is emotion" said by western aesthetician Rodin and "creation always bases on love" said by Mr. Lu Xun all base on the same understanding and truth, namely the shape of various artistic images in artistic works gathers the aesthetic judgment and reflection of feeling of creation subject for vital phenomenon. That is to say, the artistic images created by aesthetic subject all contain strong and prominent aesthetic emotions. It by no means objectively and simply reemerges with real life. It is obvious that in the field of design, the shape of artistic image and the expression of aesthetic emotion are unified. The meaning of "moving people by emotion" is that the design of artistic works should firstly move people emotionally, and make subjects of reception (the audiences) resonate emotionally as well.

On the other hand, from the perspective of aesthetics of artistic symbol, any artistic work of design is particular thing embodied by creation subject (the designer in aesthetic subject) through specific artistic symbols, and can reflect the nature of people's universal emotion, even though the emotion that serves as the essential connotation of art also has certain abstract meaning. Susanne K. Langer thinks that "In order to reach the objective, the art should see through clearly and understand the essence of emotional life. All the understandings need abstraction. Abstraction is to abandon the occasional and non-essential factors in real and specific emotions. In reality, what contained by art is just the emotion abstracted from the subjective experience for people to observe." [2] This statement strongly proves the above arguments that "art is the creation of emotional symbols of human beings" and "emotional beauty is the highest state in design".

The artistic symbols of design are also a kind of "signified" symbols. Except for the fact that its referential meaning (things indicated by it) has similarity on forms or the consistency on logical structure, it is more important that the special artistic symbols show the nature people's universal emotion that is easy for us to feel and grasp, or called the concept of human emotions. This is because:

- In integral artistic works of design, artistic symbols of design show specific aesthetic images full of emotions, which embody emotional beauty containing specified meaning and temperament;

- Artistic symbols of design can realize the formalization or objectification of human emotions and experience, thus help people to find and grasp through rational intuition of their own;

- As with other artistic forms, the presentational symbols of design art is an expressive perceptual form that expresses the concept of human emotions. Although it doesn't have the properties and characteristics of inferential symbols, it is abstracted. It is just the abstracted existence that makes us understand the concept of human emotions perceived and understood by creation subject of design art;

- The representation of artistic works of design is to use the design symbols to objectify the subjective things and change emotions into things that are easy for us to appreciate.

\section{REFERENCES}

[1] Wu Feng: Art Symbol Aesthetics [M], Beijing: Beijing Broadcasting Institute Press, page 133, 2002

[2] Wu Feng: Art Symbol Aesthetics [M], Beijing: Beijing Broadcasting Institute Press, page 13, 2002

[3] Chen Wangheng: Art and Design Aesthetics [M], Wuhan: Wuhan University Press, 2002

[4] Liu Shucheng: Basic Theory of Aesthetics [M], Shanghai: Shanghai People's Publishing House, 2001

[5] Lu Ying: History of Visual Communication Design and Aesthetics [M], Beijing: China Remin University Press, 2000

[6] Zhang Liguo: Design and Art Aesthetics [M], Jinan: Shandong Education Press, 2002

[7] Zhu Di: Contemporary Western Aesthetics [M], Beijing: People's Publishing House, 1984 